Commentary

\title{
From Urban Façade to Green Foundation: Re-Imagining the Garden City to Manage Climate Risks
}

\author{
Rob Swart ${ }^{1, *}$, Wim Timmermans ${ }^{1}$, Jos Jonkhof ${ }^{1}$ and Hasse Goosen ${ }^{2}$ \\ ${ }^{1}$ Wageningen Environmental Research, Wageningen University \& Research, The Netherlands; \\ E-Mails: rob_swart@kpnmail.nl (R.S.),wim.timmermans@wur.nl (W.T.), j.f.jonkhof@ziggo.nl (J.J.) \\ ${ }^{2}$ Climate Adaptation Services, The Netherlands; E-Mail: hasse@climateadaptationservices.com \\ * Corresponding author
}

Submitted: 14 April 2021 | Accepted: 25 April 2021 | Published: 14 October 2021

\begin{abstract}
Climate risk management evolves rapidly from one additional challenge for urban planning into a radical driver of urban development. In addition to fundamental changes in urban planning to increase long-term resilience, the creation of new opportunities for sustainable transformation is imperative. While urban planners increasingly add climate risks to their menu, implementation of effective action is lagging. To reduce urban infrastructure's vulnerability to heat and flooding, cities often rely on short-term incremental adjustments rather than considering longer-term transformative solutions. The transdisciplinary co-development of inspiring urban visions with local stakeholders over timescales of decades or more, can provide an appealing prospect of the city we desire-a city that is attractive to live and work in, and simultaneously resilient to climate hazards. Taking an historic perspective, we argue that re-imagining historical urban planning concepts, such as the late $19^{\text {th }}$-century garden city until early 21 st century urban greening through nature-based solutions, is a pertinent example of how climate risk management can be combined with a wide-range of socio-economic and environmental goals. Climate knowledge has expanded rapidly over the last decades. However, climate experts mainly focus on the refinement of and access to observations and model results, rather than on translating their knowledge effectively to meet today's urban planning needs. In this commentary we discuss how the two associated areas (urban planning and climate expertise) should be more fully integrated to address today's long-term challenges effectively.
\end{abstract}

\section{Keywords}

climate adaptation; climate services; garden city; historical urban planning context; nature-based solutions; resilience; urban transformation

Issue

This commentary is part of the issue "Towards Green(er) Cities: Contextualizing Green Benefits for Urban Spaces and Contemporary Societies" edited by Juaneé Cilliers (University of Technology Sydney, Australia).

(C) 2021 by the authors; licensee Cogitatio (Lisbon, Portugal). This commentary is licensed under a Creative Commons Attribution 4.0 International License (CC BY).

\section{Introduction: Climate Change Response and the Reimagination of the Garden City}

In this commentary we highlight the pervasive impact that climate change will have on city design and the potential of greening as a transformative response. More than a century ago, the publication "Garden Cities of Tomorrow" (Howard, 1902) signalled the start of the urban greening movement. Over time, many other new city planning paradigms emerged and faded. Now, new challenges give a boost to the reimagination of green cities. Continuing global urbanisation is projected to add another 2.5 billion people to urban areas by 2050 (UN, 2018), with increasing demand for additional land by a factor of $1.8-5.9$ by 2100 (Gao \& O'Neill, 2020). "The modern-city model that took hold globally in the twentieth century has outlived its usefulness. It cannot solve the problems it helped to create-especially global warming" (Plastrik \& Cleveland, 2018 , p. xi). Below, we elaborate the ramifications for urban planners and climate experts. 


\section{Shifting Urban Planning Paradigms}

Urban planning has a long history of new priorities and perspectives (Figure 1). In the context of this thematic issue, we take the garden city concept (Howard, 1902) as starting point, a response to the unhealthy and overcrowded cities of the times, combining the advantages of town and countryside to provide a better alternative for the working class (Kohout \& Kopp, 2020). Mumford (1938) suggested the establishment of a regional "bio-technic" order which would renew mankind's association with nature. In the same period, Le Corbusier started the innovative movement of the functional city as a laboratory for new urban concepts to transform the urban environment to fit modern times (van Es et al., 2014). Car use infrastructure had to be combined with the need for large numbers of dwellings as well as green space, clean air, and proximity of citizens to natural spaces. After WWII, the emphasis of urban planning shifted further away from nature towards post-war reconstruction, such as building adequate housing and the expansion of private car use, with accessibility a top priority for urban (infra-)structural developments. From the 1960s, economic growth put its mark on rapidly growing cities as centres of business and technological innovation, triggering the development of concepts such as organic communitybased urban development (Jacobs, 1961), ecological urban design (McHarg, 1969), cities as complex systems of interrelated-including environmental-components (von Bertalanffy, 1969), and urban metabolism (Coelho \& Ruth, 2006).

Towards the 1980s, the negative consequences of economic growth, such as increasing air and water pollution, came to the fore. The 1992 Earth Summit gave new impetus to reduce the environmental impact of cities and promote sustainable development. Municipal governments in industrialised countries adopted climate change as a policy issue, initially mainly focusing on mitigation by proposing energy- or carbon-neutral, or climate-smart, cities. When climate hazards were projected to increase and urban developments had already increased exposure to these hazards in many places, adaptation plans started to promote resilient or climateproof cities. A plethora of concepts addressed the rapidly emerging challenges, including future cities, eco cities, smart cities, intelligent cities, sustainable cities, compact cities, liveable cities, digital cities, innovative cities, green cities, and green urbanism, to name a few (e.g., Moir et al., 2014). City networks were established to exchange information on the experience of implementing these concepts.

\section{From Climate Science to Urban Climate Services}

When Howard introduced the garden city concept, he may have been unaware that around the same time in Sweden, Arrhenius (1897) predicted that fossil fuel combustion with associated $\mathrm{CO}_{2}$ emissions would lead to global warming. It would take almost a century before the two issues became profoundly intertwined (Figure 1). Until well after WWII, climate science focused mostly on natural changes. However, from the 1970s, improved modelling capabilities suggested that the planet would warm as a result of human activities. The first scientific assessment report of the Intergovernmental Panel on Climate Change in 1990 triggered the establishment of the United Nations Framework Convention on Climate Change in 1992. At that time, the prevailing hope and

Timeline: $19001910192019301940 \quad 1950 \quad 1960 \quad 1970 \quad 198019902000201020202030$

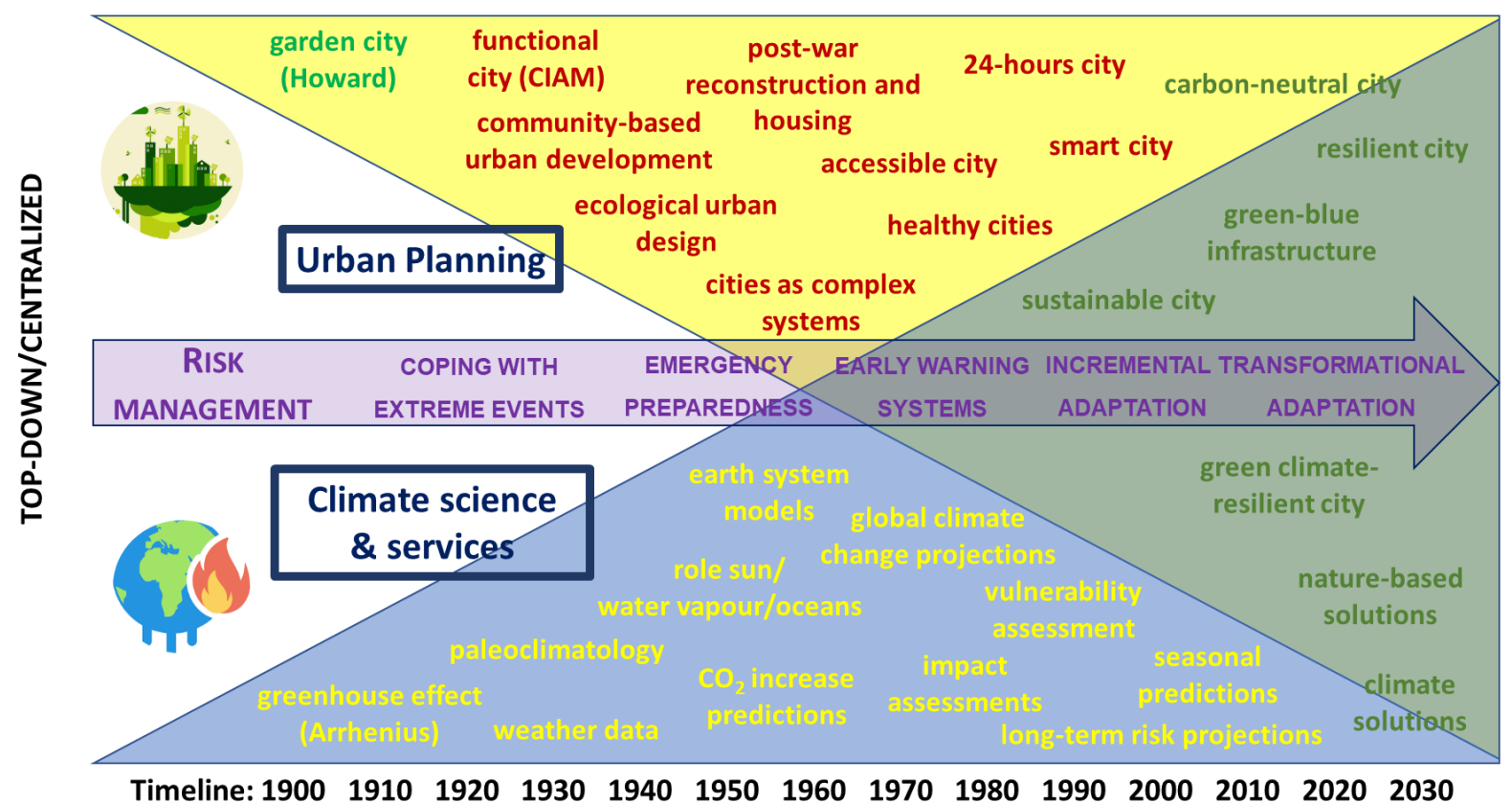

Figure 1. Integrating urban planning concepts, climate science, and action over time. 
belief was that climate change impacts could largely be prevented, hence the initial emphasis on mitigation. Simultaneously, knowledge about climate change impacts expanded, partly as a result of improved modelling capabilities in important areas such as hydrology and ecology. As actual climate impacts became more and more visible and the hopes for quick mitigation evaporated, adaptation came to the fore. To support adaptation among those vulnerable to climate impacts, the concept of "climate services" was introduced in the last decades of the 20th century (Brasseur \& Gallardo, 2016; Zillman, 2009). These services were established to improve access to weather and climate data, presenting them in ways suitable for users with more limited knowledge and skills. In Europe, in particular, the scope of climate services was expanded to include the improvement of climate resiliency across the continent as well as to generate jobs. Urban planners are a major target and user group for these climate services.

\section{From Incremental Climate Adaptation to Resilient Urban Transformation}

Since the turn of the century, urban planners and climate experts cautiously started to connect. However, we argue that the urgency and pervasiveness of climate change requires integration between these two groups to be accelerated and deepened (Figure 1). Four challenges need to be addressed. Firstly, systemic change is needed to advance urban planning and development towards longer-term transformation. Arguably, in many cities, the climate change response is increasingly connected to other environmental, social, and economic challenges such as globalisation, ageing, technological developments, geo-political change, mobility, ecological risks, resource limitations, inequality, social tensions, and changing institutional and governance frameworks (Moir et al., 2014). However, merely connecting is becoming insufficient: Climate change forces urban planning to transform from addressing climate risks within the constraints of existing urban systems towards redesigning the urban system to address long-term challenges, in particular climate change-from "function follows system" to "system follows function."

Secondly, the unfolding of climate change requires extending the time and space horizons of urban agendas. Considering the possible risks of climate change mainly in terms of short- to medium-term timescales, incremental measures often still prevail: Quick-win measures that reduce risks without changing overall city design. Examples include raising dykes or other flood protection infrastructure, enlarging drainage systems, or refurbishing buildings for cooling. These measures are often insufficient to avoid long-term impacts and may even hinder effective transformative solutions. In addition, climate change requires expanding the spatial scope of planning, from the level of neighbourhoods to the scale of the city and its hinterland, which is important for the sus- tainable availability of resources such as water and food. Views on the relationship between cities and the green open space around them have fluctuated over time. Climate change also forces us to reconsider this relationship. Elmqvist et al. (2021) argue that to boost sustainability, new urban challenges such as climate change require rescaling diversity (e.g., food supply, blue-green infrastructure), enhancing urban-rural connectivity and new cross-scale interactions, and better management of increasing complexity.

Thirdly, the framing of climate change and the associated planning process should be reshaped to create sustainable solutions. The (positive) creation of opportunities can be a more effective climate response perspective than a narrow (negative) focus on risk management. Climate-resiliency is often addressed in a defensive way, such as "bouncing back" in order to maintain a city's basic functions and structures in the face of climate risks. "Bouncing forward" may be a more positive approach, transforming a city's economic, social, and political functions and structures to be better prepared for a future in which adaptive and participatory management allows navigation towards an attractive and resilient city (Plastrik \& Cleveland, 2018). Urban planning that builds cities' resilience to new weather conditions can transform these spaces into powerful instruments for sustainable development (Climate-Fit City, 2018). This requires innovative urban visioning, using transdisciplinary foresight methods and tools (McPhearson et al., 2017), and the evolution from an initially expert-driven, centralised, top-down urban planning process to a participatory, decentralised, bottom-up process with the engagement of a wide variety of stakeholders (Figure 1).

Fourthly, this transdisciplinarity requires climate services to be widened and transformed, integrating them with long-term urban planning. Climate experts have important knowledge that can support urban transformation beyond providing climate data. They can help inform choices for urban investments such as the location of new urban areas and infrastructure (e.g., flood risk); the design of buildings, neighbourhoods, and green spaces (e.g., temperature implications of specific designs of buildings and city districts and climate-sensitivity of plants and trees); and the connectivity between urban areas and their hinterland. Process-wise, in order to meet their potential, climate services would have to develop from "science-driven and user-informed" to "user-driven and science-informed" (Street, 2016).

\section{From Façade to Foundation: Urban Greening and Resilient City Transformation}

If the above challenges are met, to what kind of urban solutions may this lead? While it may not be the only solution, we advance pervasive urban greening as a key avenue for the design of a sustainable, inclusive, economically successful, climate-fit, and attractive urban environment. Many concepts have been proposed, including 
ecological engineering, urban forestry, ecosystem-based adaptation, green/blue infrastructure, renaturing cities, and green urbanism. Often, these concepts highlight one or more themes (Escobedo et al., 2019), such as biodiversity, mitigation (carbon-sequestration), or leisure. Nature-based solutions are a recent addition to these concepts that integrate environmental, social, and economic objectives in a comprehensive manner. They are inspired and supported by nature, but also address costeffectiveness by simultaneously providing environmental, social, and economic benefits and helping to build resilience (Dorst et al., 2019; EC, 2015). Different forms of (peri-)urban agriculture via gardens and farms (Smit et al., 1996) should also be included explicitly in the design of transformed cities as they address various issues related to climate change, encompassing environmental, social, and economic benefits.

As summarised above, over the course of more than a century many urban planning concepts representing different foci and perspectives have been proposed. Nature-based solutions connect to many of these concepts which are often still relevant today and worth revisiting, starting with, but not limited to, the garden city. This short commentary does not do justice to all possible approaches, and eventual choices will necessarily depend on local circumstances and priorities.

To conclude, we synthesise four recommendations from the above:

- Long-term climate change should be seen as a guiding determinant of future urban design rather than just one among many boundary conditions for urban planners. Both preparedness for extreme weather events and incremental measures to adapt to a changing climate can often be accommodated within the existing urban structure. However, realising a climate-resilient city for the longer term changes the rules of the game.

- Climate change requires an integrated, transdisciplinary, long-term approach to planning, from the scale of buildings and neighbourhoods to the peri-urban region. Climate change intersects with many other urban challenges, including citizen housing, health, inequality, employment, accessibility, leisure, greening, and technological development. As climate change also affects the provision of external resources and local risks are affected by climate impacts in the urban hinterland, climate change does not only require expansion of time but also spatial horizons.

- Climate change provides opportunities for positive urban visions and designs. Climate change does not necessarily have to be seen solely as a threat to urban development but can also be viewed as an opportunity for transformational change that addresses other objectives. This requires the co-development of positive visions for attractive, safe, and thriving future cities by citizens, local companies, urban planners, ecologists, and climate service providers. In particular, the scope of climate services needs to be widened to achieve this vision.

- Urban greening through nature-based solutions and urban agriculture addresses climate change mitigation and adaptation in addition to multiple other objectives. Designing urban green infrastructure in a sustainable and effective fashion requires an understanding of the future climate and its implications for mitigation and adaptation. Climate change suggests reinventing the garden city in novel ways, with nature-based solutions and urban agriculture as key integrating concepts.

\section{Acknowledgments}

We acknowledge the European Research Area for Climate Services project INNOVA (Grant Agreement No. 690462) for the financial support for this work. We thank Gary Anderton of Wageningen in'to Languages for checking the language.

\section{Conflict of Interests}

The authors declare no conflict of interests.

\section{References}

Arrhenius, S. (1897). On the influence of carbonic acid in the air upon the temperature of the earth. Publications of the Astronomical Society of the Pacific, 54(14), 14-24. http://doi.org/10.1086/121158

Brasseur, G. P., \& Gallardo, L. (2016). Climate services: Lessons learned and future prospects. Earth Future, 4(3), 79-89. https://doi.org/10.1002/2015EF000338

Climate-Fit City. (2018). The right data, the right way. Brochure for urban climate adaptation services. https://project.climate-fit.city/wp-content/uploads/ 2020/07/CFC-brochure-v4.pdf

Coelho, D., \& Ruth, M. (2006). Seeking a unified urban systems theory. WIT Transactions on Ecology and the Environment, 93, 179-188. https://doi.org/10.2495/ SC060171

Dorst, H., van der Jagt, A., Raven, R., \& Runhaar, R. (2019). Urban greening through nature-based solutionsKey characteristics of an emerging concept. Sustainable Cities and Society, 49, Article 101620. https:// doi.org/10.1016/j.scs.2019.101620

EC. (2015). Towards an EU research and innovation policy agenda for nature-based solutions \& re-naturing cities-Final report of the Horizon 2020 expert group on 'nature-based solutions and re-naturing cities.'

Elmqvist, T., Andersson, E., McPhearson, T., Bai, X., Bettencourt, L., Brondizio, E., Colding, J., Daily, G., Folke, C., Grimm, N., Haase, D., Ospina, D., Parnell, S., Polasky, S., Seto, K. C., \& Van Der Leeuw, S. (2021). Urbanization in and for the Anthropocene. npj Urban 
Sustainability, 1, Article 6. https://doi.org/10.1038/ s42949-021-00018-w

Escobedo, F. J., Giannico, V., Jim, C. Y., Sanesi, G., \& Lafortezza, R. (2019). Urban forests, ecosystem services, green infrastructure and nature-based solutions: Nexus or evolving metaphors? Urban Forestry \& Urban Greening, 37, 3-12. https://doi.org/ 10.1016/j.ufug.2018.02.011

Gao, J., \& O'Neill, B. C. (2020). Mapping global urban land for the 21st century with data-driven simulations and shared socioeconomic pathways. Nature Communications, 11, Article 2302. https://doi.org/ 10.1038/s41467-020-15788-7

Howard, E. (1902). The garden city of tomorrow. S. Sonnenschein \& Co.

Jacobs, J. (1961). The death and life of great American cities. Random House.

Kohout, M., \& Kopp, J. (2020). Green space ideas and practices in European cities. Journal of Environmental Planning and Management, 63(14), 2464-2483. https://doi.org/10.1080/09640568.2020.1716698

McHarg, I. (1969). Design with nature. Wiley.

McPhearson, T., Iwanie, D. M., \& Bai, X. (2017). Positive visions for guiding urban transformations toward sustainable futures. Current Opinion in Environmental
Sustainability, 22, 33-40. http://dx.doi.org/10.1016/ j.cosust.2017.04.004

Moir, E., Moonen, T., \& Clark, G. (2014). What are future cities? Origins, meanings and uses. Government Office of Science.

Mumford, L. (1938). The culture of cities. Harcourt, Brace and Company.

Plastrik, P., \& Cleveland, J. (2018). Life after carbon-The next global transformation of cities. Island Press.

Smit, J., Ratta, A., \& Nasr, J. (1996). Urban agriculture: Food, jobs, and sustainable cities. United Nations Development Programme.

Street, R. B. (2016). Towards a leading role on climate services in Europe: $A$ research and innovation roadmap. Climate Services, 1, 2-5. https://doi.org/10.1016/ j.cliser.2015.12.001

UN. (2018). 2018 revision of world urbanization prospects. van Es, E., Harbusch, G., Maurer, B., Perez, M., Somer, K., \& Weiss, K. (2014). Atlas of the Functional City: CIAM 4 and comparative urban analysis. THOTH Publishers and gta Verlag.

von Bertalanffy, L. (1969). General system theory: Foundations, development, applications. George Braziller.

Zillman, J. (2009). A history of climate activities. WMO Bulletin, 58(3), 141-150.

\section{About the Authors}

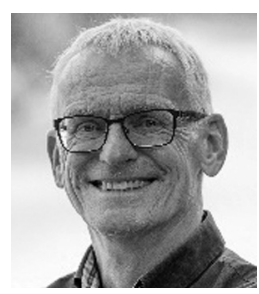

Rob Swart worked between research and policy in the areas of environment, climate change, and sustainable development for more than four decades. He graduated as an environmental engineer from Delft University of Technology in 1980 and worked, inter alia, for the Pan American Health Organization, the Netherlands Environmental Assessment Agency, the Intergovernmental Panel on Climate Change, the European Environment Agency, and Wageningen Environmental Research. After retiring in 2020 he remained associated with the latter institution. A core theme in his work is the connection between climate change response and broader sustainability themes.

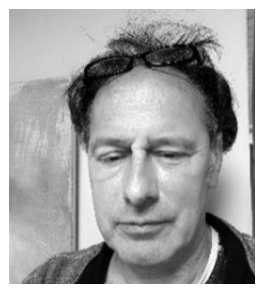

Wim Timmermans worked for 15 years as a sustainability policymaker for Dutch cities and 20 years as a senior researcher (WUR) and associate professor (Van Hall-Larenstein University of Applied Sciences) on green urbanism, sustainable planning, and climate adaptation. He holds a degree in innovative land use and green planning from the University of Santiago de Compostela. He was active in his local town council and actively follows local politics as a journalist. His experience enables him to reflect on urban climate adaption from science, policy, politics, and people's perspectives.

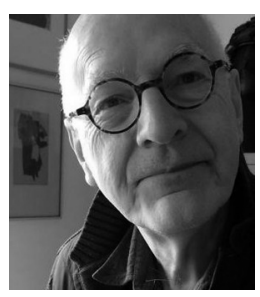

Jos Jonkhof, a sustainable urban planning engineer from Delft University of Technology, worked at the Dutch Ministry of Housing, Urban Planning and Environment in the 1980s and 1990s and as researcher and conceptual designer at Wageningen University \& Research from 2000. After retirement, he was involved in conceptual design projects for municipalities, regional, and national water authorities. From 2012-2016, he contributed to the French governmental Research Programme Land Transport Infrastructures, Ecosystems and Landscapes. He focuses on the relationship between conceptual planning development and the ecology of knowledge in research and planning.

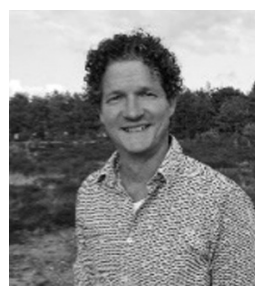

Hasse Goosen (PhD), as director of Climate Adaptation Services Foundation, has supported numerous governments at different administrative levels in the development of adaptation plans and strategies. Hasse played a key role in the Dutch Delta Program Spatial Adaptation, helping with the introduction of the stress test and climate atelier approach in the Netherlands and organising dozens of climate workshops with various municipalities, provinces, and water authorities. Hasse has experience in the development and application of planning and decision support tools and techniques for adaptation to climate change. 